\title{
Diagnostic Accuracy of the Primary Care Screener for Affective Disorder (PC-SAD) in Primary Care
}

\author{
Angelo Picardi ${ }^{1, *}$, D.A. Adler ${ }^{2,3,4}$, W.H. Rogers ${ }^{2}$, I. Lega ${ }^{1}$, M.P. Zerella ${ }^{5}$, G. Matteucci ${ }^{5}$, L. Tarsita- \\ $\mathrm{ni}^{5}$, M. Caredda ${ }^{5}$, A. Gigantesco ${ }^{1}$, M. Biondi ${ }^{5}$ and the SET-DEP Group $\$$ \\ ${ }^{I}$ Mental Health Unit, Centre of Epidemiology, Surveillance and Health Promotion, Italian National Institute of Health, \\ Rome, Italy \\ ${ }^{2}$ The Health Institute, Institute of Clinical Research and Health Policy Studies, Department of Medicine, Tufts Medical \\ Center (Tufts MC), Boston, MA, USA \\ ${ }^{3}$ Tufts University School of Medicine, Boston, USA \\ ${ }^{4}$ Department of Psychiatry, Tufts MC, Boston, MA, USA \\ ${ }^{5}$ Department of Psychiatric Sciences and Psychological Medicine, 'Sapienza' University of Rome, Rome, Italy
}

\begin{abstract}
Background: Depression goes often unrecognised and untreated in non-psychiatric medical settings. Screening has recently gained acceptance as a first step towards improving depression recognition and management. The Primary Care Screener for Affective Disorders (PC-SAD) is a self-administered questionnaire to screen for Major Depressive Disorder (MDD) and Dysthymic Disorder (Dys) which has a sophisticated scoring algorithm that confers several advantages. This study tested its performance against a 'gold standard' diagnostic interview in primary care.

Methods: A total of 416 adults attending 13 urban general internal medicine primary care practices completed the PC$\mathrm{SAD}$. Of 409 who returned a valid PC-SAD, all those scoring positive $(\mathrm{N}=151)$ and a random sample $(\mathrm{N}=106)$ of those scoring negative were selected for a 3-month telephone follow-up assessment including the administration of the Structured Clinical Interview for DSM-IV-TR Axis I Disorders (SCID-I) by a psychiatrist who was masked to PC-SAD results.

Results: Most selected patients $(\mathrm{N}=212)$ took part in the follow-up assessment. After adjustment for partial verification bias the sensitivity, specificity, positive and negative predictive value for MDD were $90 \%, 83 \%, 51 \%$, and $98 \%$. For Dys, the corresponding figures were $78 \%, 79 \%, 8 \%$, and $88 \%$.

Conclusions: While some study limitations suggest caution in interpreting our results, this study corroborated the diagnostic validity of the PC-SAD, although the low PPV may limit its usefulness with regard to Dys. Given its good psychometric properties and the short average administration time, the PC-SAD might be the screening instrument of choice in settings where the technology for computer automated scoring is available.
\end{abstract}

Keywords: Depression, Diagnosis, Primary care, Public health.

\section{INTRODUCTION}

Depressive disorders are relatively common in the general population [1] and are the fourth leading cause of worldwide disease burden, as they account for $12 \%$ of all total years lived with disability [2]. The cost of depression

\footnotetext{
*Address correspondence to this author at the Italian National Institute of Health, Centre of Epidemiology, Surveillance, and Health Promotion, Mental Health Unit, Viale Regina Elena, 299 - 00161 Rome, Italy;

Tel: +39 06 49904200; Fax: +39 06 49904182; E-mail angelo.picardi@iss.it

${ }^{\$}$ The SET-DEP Group includes: A. Picardi. M. Biondi, M. Cerbo, A. Gaddini, A. Gigantesco, F. Spandonaro. M. Caredda, A. Cavallo, A. Crescenzi, I. Lega, G. Matteucci, B. Polistena, L. Tarsitani, M.P. Zerella. I. Berardelli, I. Cascavilla, D. Del Re, C. Fini, L. Leoncini. S. Baccarini, F. D’Andrea, M. Di Fonso, R. Dolfi, A. Guerani, D. Mandolini, G. Marri, L. Pagano, M. Pagliarini, M.L. Paoletti, A. Pes, S. Raspa, M. Sabatini, U. Salomone, P. Ventura.
}

has been estimated at $\$ 83.1$ billion in the USA [3] and $£ 9$ billion in England [4], most of which was attributable to time off work. In primary care [5], as well as in other nonpsychiatric medical settings [6], their prevalence is high. In the PREDICT study carried out in six European countries, the 12-month cumulative incidence of DSM-IV major depression in screened GP attendees was 7.7\% [7].

Given that effective treatments are available, the importance of their early detection and treatment cannot be overstated and indeed several authors have called for the better identification and treatment of depression [8]. Primary care physicians are often the first, and not rarely the only, health professionals that are contacted by depressed patients [9]. However, the accuracy of depression recognition by primary care practitioners and other non-psychiatrist physicians is not satisfactory $[10,11]$. Hence, improving diagnostic efficiency for depressive disorders in primary care and other non- 


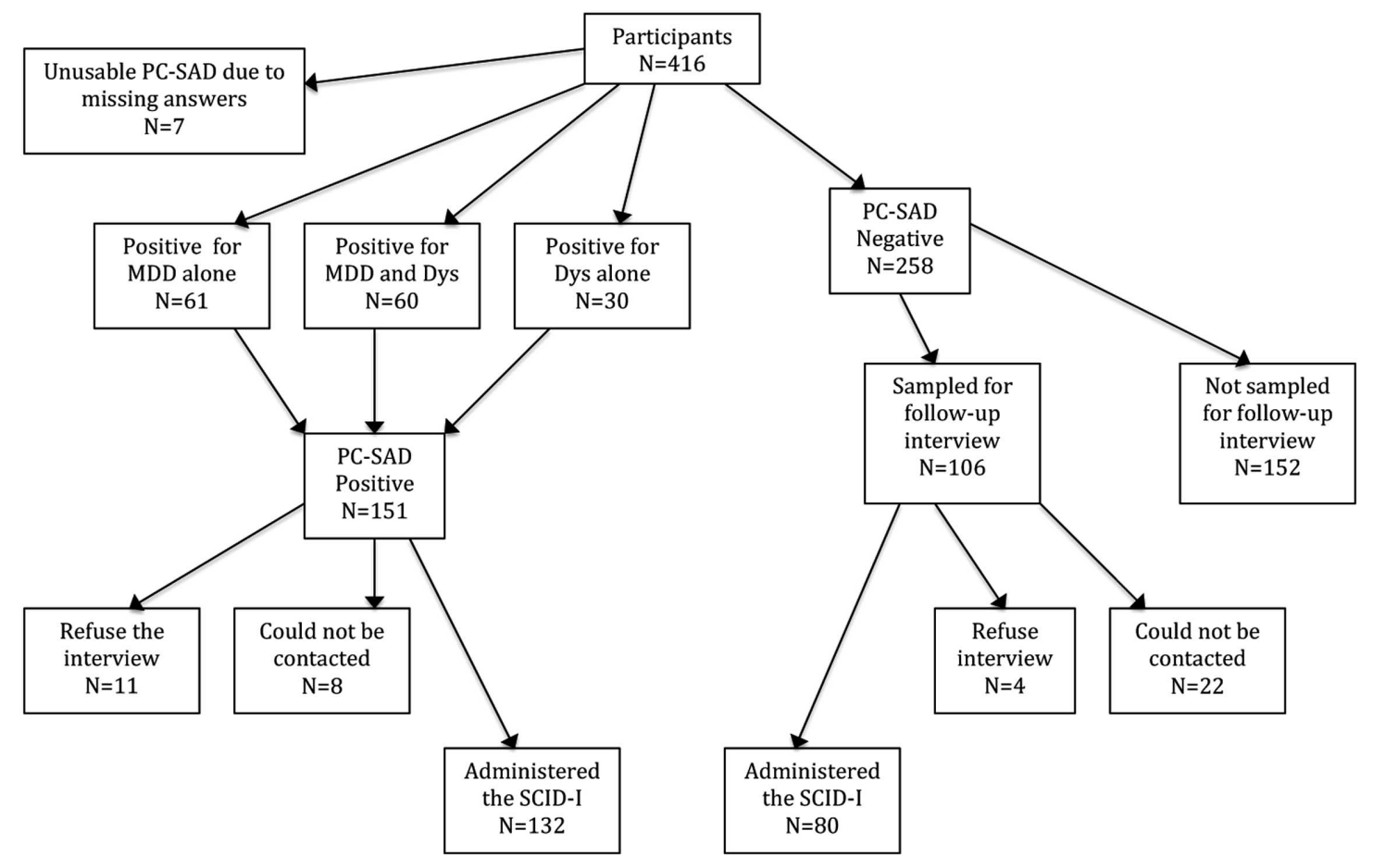

Fig. (1). Flow chart of the study.

psychiatric medical settings is an important public health objective.

In recent years, screening for depression in nonpsychiatric medical settings has gained acceptance as a first step towards improving depression recognition and management [12], and several screening tools have been developed. However, not all depression screeners are suitable for routine use $[13,14]$. Lengthy self-administered questionnaires as well as clinician-administered instruments are impractical, while the instruments that do not provide clinicians with a list of the symptoms of depression that are present in each case make physician follow-up more difficult and timeconsuming. Instruments such as the 9-item Patient Health Questionnaire (PHQ-9), a short questionnaire that is worded closely after the DSM-IV summary criterion for each MDD symptom, constitute a better approach to the problem. However, even the PHQ-9 has a limitation in the complexity of various items. Given that the instrument uses a single item to inquire about both polarities of vegetative symptoms, it includes several multiple concept questions that require the patient to integrate various emotions and behaviours into a summary answer, which may put less-educated subjects into some trouble.

The Primary Care Screener for Affective Disorders (PCSAD) [14] is a 37-item self-administered questionnaire designed to screen for Major Depressive Disorder (MDD) and Dysthymic Disorder (Dys) in primary care. It makes use of technological advances [15] and has a sophisticated scoring algorithm that confers several advantages, such as the possibility to yield valid results even if many items are left unanswered. Its validity was first tested against other established screening questionnaires in health plan members, primary care outpatients, and psychiatric patients [14], and then was tested against a standardised psychiatric interview in derma- tological inpatients [16]. Also, valid and reliable continuous measures of depression severity derived from the PC-SAD are available $[17,18]$. However, no study has yet validated the PC-SAD against a standardised diagnostic interview in a primary care setting. This study aimed at filling this research gap by testing the performance of the PC-SAD against a 'gold standard' diagnostic interview in a sample of primary care patients.

\section{METHODS}

\section{Patients and Procedure}

A convenience patient sample consisting of adults attending 13 urban general internal medicine primary care practices took part in this diagnostic validity study. Participants were recruited by fliers posted in the waiting room while attending their regular appointments. They were offered to participate in a program for early detection of depression called 'SET-DEP' (Screening and Enhanced Treatment for Depression) and they provided written informed consent to participate in the study according to procedures approved by the Italian National Institute of Health ethical committee.

Fig. (1) shows the flow of patients through the study. A total of 416 primary care patients aged 18-65 years were included in the study and completed the PC-SAD in the waiting room. Only 7 PC-SAD questionnaires were unusable because of missing answers. Of the 409 participants with a valid PC-SAD, 121 were positive for MDD, either with $(\mathrm{N}=61)$ or without $(\mathrm{N}=60)$ positivity also for Dys, and 30 for Dys alone. The remaining 258 participants were negative for both MDD and Dys.

All patients with a positive PC-SAD result and a random sample of $41 \%(\mathrm{~N}=106)$ of those scoring negative on the PC$\mathrm{SAD}$ were selected for a follow-up mental health assessment 
to be performed by telephone by a psychiatrist three months after PC-SAD completion, which included the Structured Clinical Interview for DSM-IV-TR Axis I Disorders, Research Version, Patient Edition (SCID-I) [18]. Two psychiatrists performed the follow-up assessments. Of 151 patients scoring positive on the PC-SAD, 132 (81\% females, mean age $47.4 \pm 11.5$ ] were administered the SCID-I, while 8 could not be contacted despite repeated attempts and 11 refused the follow-up interview. Of the 19 patients with a positive PCSAD who did not undergo the follow-up assessment, 11 were positive for MDD, either with $(\mathrm{N}=6)$ or without $(\mathrm{N}=5)$ positivity also for Dys, and 8 for Dys alone. There were no differences in gender, age, education, or marital status between the patients who underwent the follow-up assessment and those who did not. Of the 106 patients with a negative PC-SAD result sampled for the follow-up assessment, 80 (69\% females, mean age $45.0 \pm 11.3)$ were administered the SCID-I, while 22 could not be contacted despite multiple attempts and 4 refused the follow-up interview. There were no differences in demographic variables between the patients who were administered the follow-up interview and those who did not, except for a higher mean age in patients who did not take part in the follow-up assessment.

\section{Instruments}

The SCID-I [19] is a clinician-administered detailed semi-structured interview that covers most Axis I disorders and is regarded as the 'gold standard' for making DSM-IV diagnoses. Several studies showed the superior validity of the SCID-I over standard clinical interviews at intake episode $[20,21]$.

The PC-SAD [14] is a short, self-administered questionnaire, constructed in accordance with DSM-IV criteria. The PC-SAD makes it possible to screen not only for MDD but also for Dysthymic Disorder (Dys). It consists of a 3-item pre-screener (two MDD questions and one Dys question, which are part of the screener score but reduce respondent burden by terminating the questionnaire if all are negative), a 26-item MDD section, and an 8-item Dys section. The PCSAD breaks down each of the nine DSM-IV symptoms of MDD into several simple items, each consisting of single concept questions, and it integrates the answers mathematically. The responses linked to a given symptom are numbered and summed, and if the sum is above a certain threshold, the patient is said to have the symptom. The questionnaire is scored using an automated system, and the scoring algorithm is built in a way that the presence of each symptom can be determined independently from the presence of missing answers to one or more items related to the symptom, provided that at least one of the items related to the symptom has been answered. Hence, the questionnaire can give valid results even if many items are left unanswered, provided that at least one item for each DSM-IV symptom is answered. Similarly for the Dys section, which is the only validated self-administered screener available that is specific for Dys.

\section{Performance of the Screening Test}

Using the SCID-I as the reference standard, we calculated the sensitivity, specificity, predictive values, and likeli- hood ratios of the PC-SAD for MDD and Dys. Sensitivity is defined as the proportion of individuals with a disease who have a positive test result, whereas specificity is the proportion of individuals without the disease who have a negative test result. The positive predictive value (PPV) is the percentage of patients with a positive test result who have the disease, while the negative predictive value (NPV) is the percentage of patients with a negative test result who are free from the disease. The likelihood ratio for a positive result represents the odds that a patient with the disease has a positive test result as compared with a patient without the disease. The likelihood ratio for a negative result represents the odds that a patient without the disease has a negative test result as compared with a patient without the disease. Differently from predictive values, sensitivity and specificity are largely independent of the setting in which a screening test is used as they are quite stable with changes in prevalence of the disease in the population, while likelihood ratios may be even more stable with changes in prevalence [22].

\section{Adjustment for Partial Verification Bias}

In studies where only a portion of patients who underwent the screening test are administered the reference standard, the estimates of sensitivity and specificity may be biased. The term partial verification bias is commonly used to describe the quantitative effect of having different fractions of patients with a positive and negative screening result receiving the reference standard. Usually, this kind of bias leads to overestimate sensitivity and underestimate specificity [23].

To adjust for partial verification bias in patients with a PC-SAD positive for depression, we relied on the missing at random assumption, i.e., that the decision to ascertain the presence of depression does not depend on any information related to true disease status other than the observed PC$\mathrm{SAD}$ result. This assumption is reasonable as the patients with a negative PC-SAD who were administered the SCID-I were randomly selected from the full sample of test negatives, and only a small proportion (12.6\%) of patients with a positive PC-SAD did not receive the SCID-I.

Under this assumption, to adjust for partial verification bias the observed test results in each test stratum are weighted by the probability that patients in that stratum were administered the SCID-I [24]. As positivity to MDD or Dys may be a measured cofactor that influenced test verification, the patients with a PC-SAD negative for MDD who did not receive the SCID-I were further stratified according to their positivity for Dys or not, and the patients with a PC-SAD negative for Dys who did not receive the SCID-I were further stratified according to their positivity for MDD or not. Then, the adjustment was made weighted according to cofactor-defined strata to derive unbiased estimates of sensitivity and specificity.

\section{RESULTS}

The results of the follow-up assessment, performed on 132 patients scoring positive and 80 scoring negative on the PC-SAD, are described in detail in Table $\mathbf{1 .}$

Of 110 patients scoring positive for MDD, 56 received a SCID-I diagnosis of MDD, and 35 of another mental disor- 
der, while only 19 had no diagnosable mental disorder. Of 22 patients scoring negative for MDD but positive for Dys, 5 had MDD as determined by the SCID-I. All 80 patients scoring negative for both MDD and Dys were free from MDD as determined by the SCID-I.

Of 77 patients scoring positive for Dys, 6 received a SCID-I diagnosis of Dys, 44 had another depressive disorder, 6 an anxiety disorder, and only 21 had no diagnosable mental disorder, of whom one had symptoms of grief in response to a recent loss. Of 55 patients scoring negative for Dys but positive for MDD, 2 had Dys as determined by the SCID-I. All 80 patients scoring negative for both Dys and MDD did not receive a SCID-I diagnosis of Dys.

Most patients with a negative PC-SAD ( $\mathrm{N}=63,80 \%)$ did not receive any DSM-IV diagnosis, while the remaining 17 were diagnosed with a mental disorder, in most cases $(\mathrm{N}=15)$ an anxiety disorder.

The performance of the PC-SAD after adjustment for partial verification bias is presented in detail in Table $\mathbf{2}$.

\section{DISCUSSION}

Consistently with previous findings on dermatological patients [16], the PC-SAD displayed excellent sensitivity and good specificity for the diagnosis of MDD as determined by the SCID-I. Also, both the likelihood ratio positive and likelihood ratio negative were better than the median values reported for other instruments [25]. The NPV was very high and the PPV was also quite high, as compared with the usual scenario where most patients screening positive do not have MDD [26]. It should be noted that the PPV is partly dependent on the prevalence of the condition in the population being tested, and that the prevalence of depressive disorders in our sample was relatively high, likely due to the fact that patients self-selected for participation in the study. Under a scenario of $8 \%$ prevalence, consistent with epidemiological studies performed in primary care settings [7, 27], the PPV would be $31 \%$. On the other hand, in general medical settings where all patients are ill and a substantial proportion have a chronic physical health problem the prevalence of depression is estimated to be as high as $24 \%$ [28], and under such a scenario the PPV would be $62 \%$.

The MDD/Dys ratio as based on PC-SAD positive screens for MDD and Dys was similar to that found in the Work and Health study [29]. With regard to SCID-based diagnoses, consistently with the finding of a much higher prevalence of MDD as compared with Dys (3:1 ratio) in the Italian general population [30], Dys was much less common than MDD in our patient sample. With respect to Dys, sensitivity and specificity were fairly satisfactory, as were likelihood ratios and the NPV. The PPV was particularly low and clearly not satisfactory, although, as also observed in our previous study [16], many false positives, despite not having a diagnosis of Dys, were actually affected by another depressive condition, so that a positive result for Dys retains clinical value as it suggests the possible presence of a depressive disorder. A possible explanation for the low PPV for Dys is that the wording of the Italian version is such that patients may too easily indicate the presence of symptoms. Although a future study testing the English version of the PC-SAD against the SCID-I would be necessary to rule out this explanation, critical examination of the relevant Italian items suggests that wording is unlikely to account for the finding of a low PPV for Dys. More likely, this finding reflects difficulties inherent in the diagnosis of Dys itself. In fact, with any self-report instrument, no matter how sophisticated, it is extremely difficult to establish the co-occurrence of several depressive symptoms for most days over a very long period of time, and it is impossible to distinguish between the longlasting depressive symptoms of chronic MDD or MDD in partial remission and those of MDD comorbid with Dys. Moving the PC-SAD cut-off for Dys may help reducing the number of false positives, but would hardly solve the problem given the difficulties involved in questionnaire-based diagnosis of Dys. Possibly, the PC-SAD section on Dys might be renamed as 'chronic depressive symptoms' so as to retain its clinical worthiness without formal diagnostic implications, given also that the nosology of chronic depression is complex and has long been a matter of controversy [31, 32]. Future studies are needed to fully elucidate this issue.

This study has some limitations. First, not all patients whose PC-SAD result was negative were administered the reference standard due to cost considerations. However, given the high sampling fraction and the use of random sampling, there is reason to believe that the missing at random assumption was satisfied, and that the adjustment for partial verification yielded unbiased estimates of sensitivity and specificity. Second, patients volunteered for participation in the study, which likely led to an increased prevalence of depression as compared to the prevalence in all patients attending the primary care practices. While this likely accounts for the finding of a particularly high PPV for MDD, the estimates of sensitivity, specificity, and likelihood ratios are reliable as these test properties are relatively unaffected by changes in disease prevalence. Third, the patients were assessed by telephone rather than face-to-face interviews. However, several studies using standardized psychiatric interviews have obtained moderate to good diagnostic agreement between telephone and in-person administration [3336]. Fourth, the time elapsed between PC-SAD completion and SCID-I administration may have led to missing some depression diagnoses. However, the SCID-I allows reliable retrospective psychiatric diagnoses and the 3-month followup interval was so short to make underdiagnosis of a recent depressive episode quite unlikely. At any rate, if some degree of underdiagnosis occurred, its impact on the results would have been conservative as it would have led to underestimate the performance of the PC-SAD.

While these limitations suggest some caution in interpreting our results, this study is the first to provide evidence of validity against a 'gold standard' for the PC-SAD in primary care patients, and corroborated the notion that the PC-SAD is a sensitive and specific screening tool for MDD and Dys, although the low PPV displayed for the latter disorder may limit its usefulness with regard to Dys.

While depression screening alone is insufficient to substantially improve patient outcomes and should be supplemented by physician case management or mental health 
Table 1. Sociodemographic and Clinical Characteristics of Patients Undergoing the Follow-Up Assessment

\begin{tabular}{|c|c|c|c|c|c|c|c|c|c|c|c|c|c|}
\hline & & \multicolumn{3}{|c|}{$\begin{array}{l}\text { Patients positive for MDD } \\
\text { alone }(\mathrm{N}=55)\end{array}$} & \multicolumn{3}{|c|}{$\begin{array}{l}\text { Patients positive for MDD } \\
\text { and Dys }(\mathrm{N}=55)\end{array}$} & \multicolumn{3}{|c|}{$\begin{array}{l}\text { Patients positive for Dys } \\
\text { alone }(\mathrm{N}=22)\end{array}$} & \multicolumn{3}{|c|}{$\begin{array}{l}\text { Patients with a negative PC- } \\
\qquad \text { SAD }(\mathbf{N}=\mathbf{8 0})\end{array}$} \\
\hline & & $\mathbf{N}$ & $\%$ & Mean \pm SD & $\mathbf{N}$ & $\%$ & Mean \pm SD & $\mathbf{N}$ & $\%$ & Mean \pm SD & $\mathbf{N}$ & $\%$ & Mean \pm SD \\
\hline \multicolumn{14}{|c|}{ Gender } \\
\hline & Male & 12 & 21.8 & & 10 & 18.2 & & 3 & 13.6 & & 25 & 31.3 & \\
\hline & Female & 43 & 78.2 & & 45 & 81.8 & & 19 & 86.4 & & 55 & 68.8 & \\
\hline Age & & & & $47.0 \pm 12.3$ & & & $47.5 \pm 12.0$ & & & $48.1 \pm 8.4$ & & & $45.0 \pm 11.3$ \\
\hline \multicolumn{14}{|c|}{ Marital Status } \\
\hline & Unmarried & 21 & 38.2 & & 25 & 45.4 & & 8 & 36.4 & & 31 & 38.7 & \\
\hline & Married & 23 & 41.8 & & 26 & 47.3 & & 7 & 31.8 & & 39 & 48.8 & \\
\hline & $\begin{array}{c}\text { Separated, divorced, or } \\
\text { widowed }\end{array}$ & 11 & 20.0 & & 4 & 7.3 & & 7 & 31.8 & & 10 & 12.5 & \\
\hline \multicolumn{14}{|c|}{ Education } \\
\hline & Primary school & 1 & 1.8 & & & & & 2 & 9.1 & & & & \\
\hline & Junior high school & 10 & 18.2 & & 6 & 10.9 & & 5 & 22.7 & & 7 & 8.8 & \\
\hline & Senior high school & 26 & 47.3 & & 31 & 56.4 & & 7 & 31.8 & & 35 & 43.8 & \\
\hline & College & 18 & 32.7 & & 18 & 32.7 & & 8 & 36.4 & & 38 & 47.5 & \\
\hline \multicolumn{14}{|c|}{$\begin{array}{l}\text { Primary psychiat- } \\
\text { ric diagnosis }\end{array}$} \\
\hline & MDD & 26 & 47.3 & & 29 & 52.7 & & 5 & 22.7 & & & & \\
\hline & MDD and Dys & 1 & 1.8 & & & & & & & & & & \\
\hline & Dys & 1 & 1.8 & & 5 & 9.1 & & 1 & 4.5 & & & & \\
\hline & $\begin{array}{l}\text { Depressive Disorder } \\
\text { NOS }\end{array}$ & 3 & 5.5 & & 5 & 9.1 & & 2 & 9.1 & & 1 & 1.3 & \\
\hline & $\begin{array}{c}\text { Bipolar Disorder NOS, } \\
\text { mixed }\end{array}$ & & & & 1 & 1.8 & & & & & & & \\
\hline & $\begin{array}{l}\text { Mood Disorder due to a } \\
\text { GMC }\end{array}$ & 1 & 1.8 & & & & & & & & & & \\
\hline & $\begin{array}{l}\text { Alcohol-induced Mood } \\
\text { Disorder }\end{array}$ & 1 & 1.8 & & & & & & & & & & \\
\hline & Mood Disorder NOS & & & & & & & 1 & 4.5 & & & & \\
\hline & $\begin{array}{l}\text { Adjustment disorder with } \\
\text { depressed mood }\end{array}$ & 2 & 3.6 & & 1 & 1.8 & & & & & & & \\
\hline & $\begin{array}{l}\text { Adjustment disorder with } \\
\text { mixed anxiety and de- } \\
\text { pressed mood }\end{array}$ & 4 & 7.3 & & 1 & 1.8 & & 1 & 4.5 & & 1 & 1.3 & \\
\hline & Panic Disorder & & & & 1 & 1.8 & & & & & 6 & 7.5 & \\
\hline
\end{tabular}


Table 1. contd...

\begin{tabular}{|c|c|c|c|c|c|c|c|c|c|c|c|c|}
\hline & \multicolumn{3}{|c|}{$\begin{array}{c}\text { Patients positive for MDD } \\
\text { alone }(\mathrm{N}=55)\end{array}$} & \multicolumn{3}{|c|}{$\begin{array}{c}\text { Patients positive for MDD } \\
\text { and Dys }(\mathrm{N}=55)\end{array}$} & \multicolumn{3}{|c|}{$\begin{array}{c}\text { Patients positive for Dys } \\
\text { alone }(\mathrm{N}=22)\end{array}$} & \multicolumn{3}{|c|}{$\begin{array}{l}\text { Patients with a negative PC- } \\
\qquad \text { SAD }(\mathrm{N}=\mathbf{8 0})\end{array}$} \\
\hline & $\mathbf{N}$ & $\%$ & Mean \pm SD & $\mathbf{N}$ & $\%$ & Mean \pm SD & $\mathbf{N}$ & $\%$ & $\operatorname{Mean} \pm$ SD & $\mathbf{N}$ & $\%$ & Mean \pm SD \\
\hline $\begin{array}{c}\text { Generalised Anxiety } \\
\text { Disorder }\end{array}$ & 2 & 3.6 & & 1 & 1.8 & & & & & 3 & 3.8 & \\
\hline Social Anxiety Disorder & 1 & 1.8 & & & & & & & & & & \\
\hline Anxiety Disorder NOS & 4 & 7.3 & & 1 & 1.8 & & & & & 5 & 6.3 & \\
\hline No DSM-IV disorder & 9 & 16.4 & & 10 & 18.2 & & 11 & 50.0 & & 63 & 78.8 & \\
\hline
\end{tabular}

MDD=Major Depressive Disorder; Dys= Dysthymic disorder; NOS=Not Otherwise Specified; GMC=General Medical Condition

Table 2. Performance of the PC-SAD

\begin{tabular}{|c|c|c|}
\hline & Major Depressive Disorder & Dysthymic Disorder \\
\hline \hline Sensitivity $(95 \% \mathrm{CI})$ & $89.8(79.6-95.5)$ & $77.8(40.2-96.0)$ \\
\hline Specificity $(95 \% \mathrm{CI})$ & $82.6(78.1-86.4)$ & $79.0(74.6-82.8)$ \\
\hline PPV $(95 \% \mathrm{CI})$ & $51.2(42.0-60.4)$ & $7.7(3.4-15.7)$ \\
\hline NPV $(95 \% \mathrm{CI})$ & $97.6(94.8-98.9)$ & $99.4(97.5-99.9)$ \\
\hline LR+ $(95 \% \mathrm{CI})$ & $5.2(4.0-6.6)$ & $3.7(2.5-5.5)$ \\
\hline LR- $(95 \% \mathrm{CI})$ & $0.12(0.06-0.24)$ & $0.28(0.08-0.96)$ \\
\hline
\end{tabular}

$\mathrm{CI}=$ Confidence interval

$\mathrm{PPV}=$ Positive predictive value

$\mathrm{NPV}=$ Negative predictive value

$\mathrm{LR}+=$ Likelihood ratio for a positive result

LR- = Likelihood ratio for a negative result

specialist involvement in order to assure accurate diagnosis, effective treatment, and careful follow-up [12], the availability and use of simple, practical, reliable and valid depression screeners is a key first step in any depression screening and management program. Many questionnaires are available to screen for depression in primary care and other nonpsychiatric medical settings [25, 28, 37-40]. The selection of a screener requires consideration of several issues, such as characteristics of the population being screened, psychometric properties of the screener, time required to complete and to score the measure, ease of use, and cost. Given its high sensitivity and specificity, the short average administration time owing to the 3-item pre-screener, and the possibility to screen not only for MDD but also for Dys if desired, the PCSAD might be the instrument of choice in settings where the technology for computer automated scoring is available.

\section{CONFLICT OF INTEREST}

The authors confirm that this article content has no conflicts of interest.

\section{ACKNOWLEDGEMENTS}

This study was supported by the Italian Ministry of Health with a grant to the National Agency for Regional Health Services (AGENAS) in the framework of the 'Pro- gramma di Ricerca Finalizzata 2006'. The authors have no conflict of interest to declare.

\section{REFERENCES}

[1] Alonso J, Angermeyer MC, Bernert S, et al. Prevalence of mental disorders in Europe: result from the europena study of the epidemiology of mental disorder(ESEMeD) project. Acta Psychiatr Scand Suppl 2004; 420: 21-7.

[2] Ustun TB, Ayuso-Mateos JL, Chatterji S, et al. Global burden of depressive disorders in the year 2000. Br J Psychiatry 2004; 184 : 386-92.

[3] Greenberg P, Kessler R, Birnbaum H, et al. The economic burden of depression in the United States: how did it change between 1990 and 2000? J Clin Psychiatry 2003; 64: 1465-75.

[4] Thomas CM, Morris S. Cost of depression among adults in England in 2000. Br J Psychiatry 2003; 183: 514-9.

[5] Katon W, Ciechanowski P. Impact of major depression on chronic medical illness. J Psychosom Res 2002;53:859-63.

[6] Picardi A, Abeni D, Melchi CF, et al. Psychiatric morbidity in dermatological outpatients: an issue to be recognized. Br J Dermatol 2000; 143: 983-91.

[7] King M, Walker C, Levy G, et al. Development and validation of an international risk prediction algorithm for episodes of major depression in general practice attendees: the PREDICT study. Arch Gen Psychiatry 2008; 65: 1368-76.

[8] Moussavi S, Chatterji S, Verdes E, Tandon A, Patel V, Ustun B. Depression, chronic diseases, and decrements in health: results from the World Health Surveys. Lancet 2007; 370: 851-8.

[9] Boerma WG, Verhaak PF. The general practitioner as the first contacted health professional by patients with psychosocial problems: a European study. Psychol Med 1999; 29: 689-96. 
[10] Cepoiu M, McCusker J, Cole MG, et al. Recognition of depression by non-psychiatric physicians - a systematic literature review and meta-analysis. J Gen Intern Med 2008;23:25-36.

[11] Mitchell AJ. Why do clinicians have difficulty detecting depression? In: Mitchell AJ, Coyne JC, Eds. Screening for depression in clinical practice. New York: Oxford University Press 2010; pp. 5782.

[12] O'Connor EA, Whitlock EP, Beil TL, Gaynes BN. Screening for depression in adult patients in primary care settings: a systematic evidence review. Ann Intern Med 2009; 151: 793-803.

[13] Mulrow CD, Williams JW Jr, Gerety MB, Ramirez G, Montiel OM, Kerber C. Case-finding instruments for depression in primary care settings. Ann Intern Med 1995; 122: 913-21.

[14] Rogers WH, Wilson IB, Bungay KM, Cynn DJ, Adler DA. Assessing the performance of a new depression screener for primary care (PC-SAD). J Clin Epidemiol 2002; 55: 164-75.

[15] Rogers WH, Lerner D, Adler DA. Technological approaches to screening and case-finding for depression. In: Mitchell AJ, Coyne JC, Eds. Screening for depression in clinical practice. New York : Oxford University Press 2010; pp. 143-59.

[16] Picardi A, Adler DA, Abeni D, et al. Screening for depressive disorders in patients with skin diseases: a comparison of three screeners. Acta Derm Venereol 2005; 85: 414-9.

[17] Rogers WH, Adler DA, Bungay KM, Wilson IB. Depression screening instruments made good severity measures in a crosssectional analysis. J Clin Epidemiol 2005; 58: 370-7.

[18] Picardi A, Adler DA, Chang H, et al. Development and preliminary validation of the PC-SAD5, a screener-derived short depression severity measure. J Eur Acad Dermatol Venereol 2012; 26: 165-71.

[19] First MB, Spitzer RL, Gibbon M, Williams JBW. Structured Clinical Interview for DSM-IV-TR Axis I Disorders, Research Version, Patient Edition. (SCID-I/P) New York: Biometrics Research, New York State Psychiatric Institute, November 2002.

[20] Fennig S, Naisberg-Fennig S, Craig TJ, Tanenberg-Karant M, Bromet EJ. Comparison of clinical and research diagnoses of substance use disorders in a first-admission psychotic sample. Am J Addict 1996; 5: 40-8.

[21] Ramirez Basco M, Bostic JQ, Davies D, et al. Methods to improve diagnostic accuracy in a community mental health setting. Am J Psychiatry 2000;157: 1599-605.

[22] Sackett DL, Haynes RB, Tugwell P, Guyatt GH. Clinical epidemiology: a basic science for clinical medicine. $2^{\text {nd }}$ ed. Hagerstown: Lippincott Williams \& Wilkins 1991.

[23] Whiting P, Rutjes AW, Reitsma JB, et al. Sources of variation and bias in studies of diagnostic accuracy: a systematic review. Ann Intern Med 2004; 140: 189-202.

[24] Pepe MS. The statistical evaluation of medical tests for classification and prediction. Oxford: Oxford University Press, 2003.
[25] Williams JW Jr, Noel PH, Cordes JA, Ramirez G, Pignone M. Is this patient clinically depressed? JAMA 2002; 287: 1160-70.

[26] Palmer SC, Coyne JC. Screening for depression in medical care. Pitfalls, alternatives, and revised priorities. J Psychosom Res 2003; 54: 279-87.

[27] Katon W, Schulberg H. Epidemiology of depression in primary care. Gen Hosp Psychiatry 1992; 14: 237-47.

[28] Meader N, Mitchell AJ, Chew-Graham C, et al. Case identification of depression in patients with chronic physical health problems: a diagnostic accuracy meta-analysis of 113 studies. Br J Gen Pract 2011; 61: e808-20.

[29] Lerner D, Adler DA, Chang H, et al. Unemployment, job retention, and productivity loss among employees with depression. Psychiatr Serv 2004; 55: 1371-8

[30] de Girolamo G, Polidori G, Morosini P, et al. Prevalence of common mental disorders in Italy: results from the European Study of the Epidemiology of Mental Disorders (ESEMeD). Soc Psychiatry Psychiatr Epidemiol 2006; 41: 853-61.

[31] McCullough JP Jr, Klein DN, Keller MB, et al. Comparison of DSM-III-R chronic major depression and major depression superimposed on dysthymia (double depression): validity of the distinction. J Abnorm Psychol 2000; 109: 419-27.

[32] Murphy DG. The classification and treatment of dysthymia. Br J Psychiatry 1991; 158: 106-9.

[33] Simon GE, Revicki D, VonKorff M. Telephone assessment of depression severity. J Psychiatr Res 1993; 27: 247-52.

[34] Wells KB, Burnam MA, Leake B, Robins LN. Agreement between face-to-face and telephone-administered versions of the depression section of the NIMH Diagnostic Interview Schedule. J Psychiatr Res 1988; 22: 207-20.

[35] Paulsen AS, Crowe RR, Noyes R, Pfohl B. Reliability of the telephone interview in diagnosing anxiety disorders. Arch Gen Psychiatry $1988 ; 45: 62-3$.

[36] Rohde P, Lewinsohn PM, Seeley JR. Comparability of telephone and face-to-face interviews in assessing axis I and II disorders. Am J Psychiatry 1997; 154: 1593-8.

[37] Gilbody S, Sheldon T, House A. Screening and case-finding instruments for depression: a meta-analysis. CMAJ 2008; 178: $997-$ 1003.

[38] Sharp LK, Lipsky MS. Screening for depression across the lifespan: a review of measures for use in primary care settings. Am Fam Physician 2002; 66: 1001-8.

[39] Roy T, Lloyd CE, Pouwer F, Holt RI, Sartorius N. Screening tools used for measuring depression among people with Type 1 and Type 2 diabetes: a systematic review. Diabet Med 2012; 29: 164-75.

[40] Thombs BD, Magyar-Russell G, Bass EB, et al. Performance characteristics of depression screening instruments in survivors of acute myocardial infarction: review of the evidence. Psychosomatics 2007; 48: 185-94.

Received: December 20, 2012

Revised: July 26, 2013

Accepted: August 07, 2013

(C) Picardi et al.; Licensee Bentham Open.

This is an open access article licensed under the terms of the Creative Commons Attribution Non-Commercial License (http://creativecommons.org/licenses/by-nc/3.0/) which permits unrestricted, non-commercial use, distribution and reproduction in any medium, provided the work is properly cited. 